Acta Universitatis Wratislaviensis No 3920

Anglica Wratislaviensia LVII, Wrocław 2019

DOI: $10.19195 / 0301-7966.57 .7$

\author{
Lech Zdunkiewicz \\ ORCID: 0000-0002-6735-2989 \\ University of Wrocław \\ molechular@gmail.com
}

\title{
Sociopaths as Antiheroes of Streaming Media
}

\begin{abstract}
Unlike their traditional counterparts, contemporary TV antiheroes are becoming increasingly non-empathetic. Despite their dislikable qualities, they succeed in attracting audiences. I consider two factors that may be influencing their popularity. The first involves viewers' increasing familiarity with storytelling techniques and their resulting gravitation towards narratives capable of challenging their story schemas. The second aspect concerns the entertainment industry's transformations. Aware of their well-watched audiences' expectations, studios are turning to novelists to pursue more defamiliarizing forms. I discuss The Assassination of Gianni Versace (2018) as an example of a series that experiments with viewers' affective responses towards its sociopathic protagonist. I argue that the writer's choices extricate Versace from the formulaic justice-is-served narrative, thus appealing to those consumers additionally motivated by, what researchers call, eudaemonic concerns.
\end{abstract}

Keywords: antihero, empathy, affective disposition theory, streaming media, enjoyment, antisocial personality disorder

In previous eras, the antihero attracted audiences precipitating the rise of the gangster formula, the film noir, or the "positive resistance" of "New Wave Hollywood" (Langford, Post-Classical Hollywood 133). Today, in the age of streaming media, the antihero's pervasiveness is once again peaking. Critically acclaimed series rankings include a number of shows that feature morally ambiguous characters. Such listings repeatedly include Game of Thrones (2011-2019), Better Call Saul (2015-), The Americans (2013-2018), House of Cards (2013-2018), and many others. ${ }^{1}$ Though this surge of interest in darker protagonists might seem like a recurrent phenomenon, the antihero's personification has clearly become more antisocial.

1 Amongst others, I refer to metacritic.com. The website aggregates reviews for media products (including TV series and films) providing a weighted average score. A link provided in the "References" section, directs to an aggregation of "most frequently mentioned [shows] by individual critics in their year-end Top Ten lists" (Dietz). I likewise include links to rankings from entertainment industry commentators Variety and Hollywood Reporter. 


\section{A recurrent phenomenon}

Over time, the set of qualities that constitute an "antihero" seems to have been redefined in accordance with the dominant model of the era. Most often they distill to the broad concept of a protagonist operating outside their society's ethical bounds, which may or may not be equated with those of the audience. Amongst others, film theorists have classified the gangster-hero of the 1930's cinema as a precursor of the many antihero variants that followed. Films like The Public Enemy (1930), Little Caesar (1931) and Scarface (1932) made for "the briefest classic period of any Hollywood genre" (Langford, Film 136). The represented protagonist was a "strong figure" haunted by his guilty conscience and a personal loss that would drive him to forfeit all in a dramatic last stand (Shadoian 29).

The renaissance gangster films, including The Godfather trilogy (1972-1990) and the Scarface remake (1983), expanded on the formula. The gangster-hero functioned allegorically as "the mirror image of American business and, by extension, capitalist democracy itself" (McDonagh 108). In contrast to the streaming media's antihero, he invariably harboured love for at least one other character, while his residual conscience compelled him to face the consequences of his own destructiveness.

Less contemptible in comparison, the film-noir hero functioned as a "good-bad character" (Flory 44). The films, including The Maltese Falcon (1941), Double Indemnity (1944) and The Postman Always Rings Twice (1946), were about a "doomed love set in a criminal or degrading world" (Duncan 16). The sexualized femme fatale along with the corrupt cityscape drew the protagonist to employ often questionable means to achieve condonable ends (Grant 26). By comparison, today's TV antiheroes step further into the morally dubious territory, breaking the law for less and less justifiable reasons.

The New Wave Hollywood reevaluated the term with its depiction of "unmotivated, drifting, alienated (anti)heroes on a journey through America," amongst others with its 1967 mainstream releases such as "The Graduate, Point Blank, and Bonnie and Clyde" (see: Horwath 83-91). Likewise framed in opposition to a system, the protagonists of A Clockwork Orange (1971) and One Flew Over the Cuckoo's Nest (1975) became "emblematic of a countercultural desire to reverse modernity." The New Wave antihero reflected antiestablishment sensibilities opposing personifications of the hypocritical parent generation, capitalistic visions, a technocracy, etc. (Simmons 135). In a sense, their "positive resistance" against malfunctioning structures may be perceived as a call for a necessary change. The same cannot be said of the emergent antisocial antihero. 


\section{The antisocial model}

Considering examples such as Dexter Morgan of Dexter (2006-2013), Walter White of Breaking Bad (2008-2013), Frank Underwood of The House of Cards (2013-2018), James and Alyssa of The End of the F***ing World (2017-) or Andrew Cunanan of The Assassination of Gianni Versace (2018), these characters emerge as a class of individuals who, apart from having singular supporters, are emotionally withdrawn from society. Unlike the majority of the mentioned protagonist-types, they are foremost defined by their limited capacity to empathize. Essentially, their unconcern with the others' "beliefs and desires" becomes their strength as they are unimpeded by the conscience that traditionally brought about their demise (Vaage 158).

As psychologist Martha Stout proposes, the said "absence of conscience" marks "a deep human division, arguably more significant than intelligence, race, or even gender" because it allows the conscienceless culprit to remain "invisible" amongst their conscientious victims. This quality, commonly referred to as sociopathy, sets the currently popular antisocial antihero apart not only from the previous era's classifications but also from a myriad of deeply-flawed protagonists. In other words, the antihero of the streaming-media age gravitates towards the sociopathic model.

\section{Enjoyment of the antihero}

Affective disposition theory (ADT) (Zillmann and Cantor) has guided investigations into narrative enjoyment and continues to be an important frame of reference. ADT proposed that "the intensity of the dispositions formed towards characters, in conjunction with the outcomes they experience, leads to enjoyment" (Janicke and Raney 486). The strength of the bond with the protagonist proportionately influences a viewer's investment in the story's outcome.

Zillmann offered a seven-step model for "affective responding during suspenseful drama", which accounts for the disposition formation in viewers. ${ }^{2}$ The second step, arguably the most questionable when considering an antihero narrative, maintains that viewers pass a "moral judgment" on characters. Based on their verdict, they form an affective disposition, negative or positive. However, this model accounts only for the enjoyment of a "traditional", that is, a morally justifiable hero.

2 Zillmann's model of disposition formation distinguishes between the following stages: (1) perception, assessment; (2) moral judgment; (3) affective disposition; (4) anticipation, apprehension; (5) perception, assessment; (6) response to outcome/emotion; (7) moral judgment. The original model accounts for variations of the viewer's disposition formation, including possible loops that may occur between various stages (407-12). 
In their 2015 research, Sophie Janicke and Arthur Raney found that viewers are prone to suspend their judgment of morally questionable protagonists for the sake of enjoyment. They argue it is the need for character "identification" that prompts what they call a "moral disengagement" (493). This supports an earlier hypothesis that it is through identification with a character that viewers are "encouraged to justify the character's immoral behaviours" (Krakowiak and Tsay 181).

The identification mechanism or "empathy" is therefore at the heart of the narrative enjoyment process. According to film theorist Margrethe Bruun Vaage, empathy has come to be equated with the viewer's understanding of the character's motivations. While researchers prefer to focus on the "emotional output of the process", that is, the viewers' attempt to "match" the emotions experienced by the characters, they overlook the more intellectual form of engagement (158). She, therefore, proposes a division of the term into "embodied" and "imaginative empathy" (167).

Embodied empathy is the "latching onto the [character's] sensuous, bodily or affective state" (Vaage 167). It is essentially the audience's involuntary response to the audiovisual stimuli that unfold on the screen. A recognizable example of an embodied empathy "facilitator" is the dolly-zoom shot characteristic of Alfred Hitchcock's Vertigo (1958). The achieved "bending" of the perspective serves to simulate the dizziness of the protagonists' sense of vertigo. Understandably, this kind of stimulus is meant to induce a more visceral engagement.

On the other hand, imaginative empathy involves the audience's puzzlement with a character. Controlled information-deprivation prompts viewers to "imagine what it would be like to be the [intriguing] other" (Vaage 167). Imaginative empathy facilitators are effective in dramatic scenes. The protagonist might undergo a trying experience but their reaction is withheld or obscured. As a result, the viewer, inclined to imagine what the character might be feeling, begins to identify with the character. Unlike embodied empathy, the imaginative process does involve active speculation. This form of connection is essential to the engagement with the antihero.

The disposition formation model accounts for the audience's empathizing with a morally justifiable character. However, it remains "limited in its ability" to explain the growing popularity of the non-empathetic antihero. As mentioned, Janicke and Raney's study ${ }^{3}$ contradicted ADT's predictions. The researchers concluded that the "identification with, and sympathy for, antiheroes was made possible through moral disengagement" (494).

3 The study was designed to test the possibility of viewers' story schemas affecting their enjoyment of antihero narratives. Subjects viewed excerpts of the television series 24 (2001-2010) depicting the protagonist, Jack Bauer. Surprisingly, they found that subjects with prior exposure to the series reported their enjoyment increased "the more unattractive and immoral" Bauer appeared to them. In comparison, those first-time viewers who reported character identification and perceived Bauer to be attractive, "extended their latitudes of moral sanction to justify the character's behaviour, thus maintaining the positive disposition necessary for enjoyment"(p. 487). In other words, participants who found Bauer relatable became more lenient in their moral assessment of his actions. 
Raney was joined by researcher Daniel Shafer to address the question of how "moral disengagement cues impacted the enjoyment process" (1028). The conducted study presented 233 participants with 3 films: The Punisher (2004), The Boondock Saints (1999), and V for Vendetta (2006). "Cue-condition" participants viewed unaltered versions of the films whereas the "no cue-condition" group viewed clips deprived of what Shafer and Raney saw to be moral disengagement cues. ${ }^{4}$ In the end, the removal of the cues did not affect the reported enjoyment. However, the study reported that the "no-cue" participants had to find other ways of judging the antihero's morality, so as not to hinder their enjoyment (1040). Researchers concluded that the lack of moral disengagement cues upset the expectations arising from participants' story schemas. Such challenging of a familiar story pattern precipitates a viewer's recalibration of their story schema (which may in itself be gratifying). I argue that Versace produces a similar effect on its viewers.

The questioning of a story schema is caused by the encounter of the unexpected. This novelty, or "extraordinary stimuli", sparks an interest more "akin to curiosity". The other form of this affect is a "sustained interest, which springs from the desire to get closer to someone or something, to engage more fully" (Ferens 115). Such desire most likely involves the imagining of what the other feels and thinks, thus drawing an interrelation between sustained interest and empathy. Moreover, there is a strong connection between the two positive affects- "interest-excitement" and "enjoyment-joy" (114). One way to interpret this is that, while the unconventionality of form may inspire curiosity, it is character identification, or empathy, that sustains interest, thus spurring the enjoyment of the narrative.

\section{Empathy-elicitation in Versace}

As the discussed studies show, empathy is central to the enjoyment of the antihero narrative, and, consequently, empathy-elicitation techniques must be constituent of such stories. Indeed, film theorists agree on several empathy facilitators. Those include misfortune-mistreatment scenes, empathy demonstration scenes, close-ups on emotional faces, point of view structures, projections, attraction scenes, moral disengagement cues, etc. ${ }^{5}$ Storytellers, among them Versace writer Tom Rob Smith,

${ }^{4}$ Being that all three films deal with the theme of vindictiveness, the moral disengagement cues included scenes "offering justification for the protagonists' immoral actions" Researchers selected the scenes in accordance with earlier findings, specifically Raney and Bryant (2002) "identified various individual difference factors (e.g. empathy, vigilantism, punitiveness) that predicted moral judgments in crime-punishment narratives" (1039-1040).

5 The idea for the misfortune-mistreatment scenes is prevalent in screenwriting handbooks, and its execution is observable in many Hollywood blockbusters' opening sequences, such as "Erin Brockovich being turned down for a job, getting a parking ticket, and getting into a car accident in the span of a couple of pages" (Iglesias 115); the "empathy demonstration scene" aims to establish the 
not only demonstrate an awareness of the empathy eliciting techniques but they seem eager to test their ability to manipulate audiences' affective responding.

The Assassination of Gianni Versace features a sociopathic protagonist based on the real-life spree-killer Andrew Cunanan. The story is told over the course of nine episodes, as an installment of the anthology series, ${ }^{6}$ American Crime Story, created by Scott Alexander and Larry Karaszewski. All of the episodes were written or co-written by the show's executive producer Tom Rob Smith. As the head writer, he admitted having envisioned the story "ultimately as a contrast between someone [Versace] who came from nothing and created so much, and someone [Cunanan] who had all this opportunity and ended up wasting it". The plot consequently oscillates between the two characters, retaining, however, Cunanan as the protagonist (Smith).

At the heart of the Versace experiment lies the play with the story's chronology. The first episode starts with the viewers' "point of familiarity with the story", that is, the murder of Gianni Versace. Unacquainted with the protagonist's background, the audience observes Cunanan's reaction to the committed crime; it is difficult to tell what emotion he is experiencing: agony or ecstasy. The scene is dramatic and its ambiguity intriguing. It prods the viewer into imagining what Cunanan might be experiencing. Thus, by enlisting an imaginative empathy facilitator, Smith creates a thread of engagement with the protagonist, albeit at this point it is more likely interest rather than empathy.

The first disruption of chronology occurs soon after the opening murder. Instead of progressing linearly, the plot takes a step back in time. The audience learns of the events that preceded Versace's murder, namely Cunanan's arrival in Miami and his attempts at building a relationship with his victim. Under such circumstances, the viewer might expect the storyteller to provide a moral disengagement cue that would enable their justification of Versace's murder. Instead, Smith aims for the opposite effect. He frustrates any possible moral disengagement by building a rapport with the antihero's victim. Among others, he employs misfortune-mistreatment and

protagonist's "humanistic qualities such as being helpful, highly intelligent, charming, witty, clever, and learned" and thus build rapport (64); "close up on an emotional face", a facilitator of embodied empathy, intends to provoke a similar emotion in viewers; "point of view structure": a cut to a character's eye-line enables viewers to "see through their eyes"; a "projection" attempts to externalize a character's disposition by means of the mis-en-scene, photography, etc. This visual focalization has the potential to affect the viewers on both embodied and imaginative levels; an "attraction scene" is the embodied empathy facilitator of which the discussed vertigo effect is an example (Vaage 160).

${ }^{6}$ Anthology series, such as American Crime Story, differ from regular serialized television in that they feature "an original plot with a new set of characters" each episode or season (Kraszewski 1). One of the advantages of having a closed-ended story told over the course of several episodes is that the writers are able to plot the entire story before its production. Such freedom is not enjoyed by series narrated over the course of many seasons; such conditions prevent writers from arriving at a definitive plot conclusion (such as the protagonist's death), and once the show has exceeded its initially plotted path, the improvised storylines remain bound by the aired material. 
empathy demonstration scenes to evoke positive affect for Versace. The character is shown to be struggling with his health, a creative block, and an ailing relationship. Moreover, Smith flaunts Cunanan's condemnable traits such as his deceptiveness and manipulative behaviour. This enacts the audience's negative moral judgment of his character. Such a procedure challenges preexisting story schemas; viewers, familiar with antihero narratives, will feel conflicted about identifying with the protagonist; those predisposed to traditional hero narratives might try to adopt Versace as the hero and Cunanan as the villain. The latter course is inhibited in episode 3.

The story moves further back in time to reveal Cunanan's preceding murder. Significantly, Smith abandons Versace's storyline; his absence as a potential main character forces the viewers to reevaluate Cunanan as the protagonist. Again, similar empathy facilitators build identification with Cunanan's victim, as Lee Miglin is depicted as a loving husband who struggles with his closeted homosexuality. Cunanan, also a homosexual, acts with ruthless vindictiveness. As the writer suggests, his motivations are paradoxically "homophobic" (Smith). This contradiction might intrigue viewers into imagining Cunanan's justifications, yet it is his moral reprehensibility that sustains the viewers' interest, as long as they can hope for his severe punishment. This remains consistent with ADT's assumption that "the intensity of the dispositions formed toward characters, in conjunction with the outcomes they experience, leads to enjoyment" (Janicke and Raney 486).

Episode 4 continues the established temporal pattern. The plot regresses a month in time to Cunanan's preceding murders. Here, Smith allows the audience the first major insight into the protagonist's motivation. Cunanan is conflicted; his infatuation with his former lover, David Madson, stands in the way of the growing inevitability of having to kill him. As Cunanan ploys for Madson's affection, the audience might come to understand that his ultimate objective is to be loved. His flaw lies in the conviction that he can obtain his goal through violence and manipulation. The relative benevolence of his objective, however, enables character identification which, for some viewers, takes hold in the final episode. Interestingly, screenwriting theorist, Karl Iglesias argues, a protagonist's love for another character, serves as the facilitator that allows writers to "create empathy with 'criminal' or anti-heroes who operate outside the law, such as mobsters" (72). Perhaps, wanting love is a similarly relatable state.

Versace's storyline resumes in episode 5, yet Cunanan's actions continue to be the narrative-drive for the remainder of the series. Again, the plot regresses to disclose Cunanan's prior attempts to manipulate his friends and sexual partners into liking him. His endeavours, significantly less malicious, include the flaunting of his pretended status. Viewers learn of his life as a male escort and his witnessing of a murder, a trauma which, as the story implies, catalyzed his aggressiveness.

The most important character revelation occurs in episode 8, which depicts $\mathrm{Cu}-$ nanan's troubled relationship with his father, Modesto. Here, Smith relates childhood events that were most formative of Cunanan's psyche. The character, portrayed by 
a child actor, is shown to be a victim of a dysfunctional upbringing. His father's favouritism divides the young Cunanan from the rest of his mistreated family. The nurtured self-entitlement serves as the basis for Cunanan's later disillusionment when he realizes his father had sheltered him from reality with personal fantasies. Smith manages to mould the events into misfortune-mistreatment scenes to facilitate empathy, this time, for Cunanan. We can observe similar measures undertaken in other series featuring murderous characters. However, in comparison, shows like Dexter and Manhunt: Unabomber (2017) gradually reveal much more severe abuses and traumas experienced by the protagonists in their formative years.

The ninth and final episode breaks the established temporal pattern by returning to the events that concluded the first episode. After Versace's murder, the police hunt ensues, and Cunanan takes refuge in a boathouse where he suffers an emotional breakdown. The viewer's connection to the protagonist is aided by embodied empathy facilitators; the attraction scenes' dramatic lighting and camerawork attempt to convey Cunanan's apprehension while projection scenes externalize the confusion of his disintegrating mental condition. In one scene, Cunanan is sitting next to a boyhood version of himself, an image that is central to the empathy-eliciting strategy. The boy-actor, Edouard Holdener, represents a visual break from the Cunanan played by Darren Criss. Viewers may feel inclined to associate the younger actor with the character's lost innocence and victimhood. To strengthen the effect, Smith provides a dramatic realization-scene during which Cunanan, while watching a televised interview with his father, reacts violently to his father's denial tactics. These measures invite viewers to pity the spree killer, without neutralizing Cunanan's repulsiveness. The formed disposition is dissonant, which invites reflection. This effect would not have been achieved if the story had been told linearly; Cunanan's victimhood would have been obscured by the atrocities he committed. The dramatic structure would have, thus, relied on viewers' desire for retribution. As such, Cunanan's death would have been mitigating, perhaps even enjoyable, for the viewer.

\section{Antihero's growing popularity}

Researchers differentiate between what they call "hedonic and eudaemonic ${ }^{7}$ motivation for entertainment consumption" (Oliver and Raney 987). The former "reflects the desire to view entertainment that elicits positively valenced affect such as humour or joy." Versace's climactic effect does not invite such a response. The resulting dissonant affective response is more consistent with eudaemonic motivations

7 "Hedonic motivation" refers to mechanisms that prompt "pleasure-seeking" viewers, whereas eudaemonic motivation describes "individuals [who] may choose media as a means of [sometimes discomforting] truth-seeking" (Oliver and Raney 985). 
reflective of "the desire to view entertainment that elicits more meaningful affective states such as contemplativeness, compassion, or even sadness" (996).

Smith's choices were intended to allow viewers' dispositions to shift from a sense of intrigue to repulsion. Only then did he attempt to build a more positive affect. As Shafer and Raney's research has shown, a traditional hero narrative does not evoke such a reaction (see figure 1). When we consider the affective involvement for a traditional hero, the test participants' range of measured "liking" did not change significantly over the course of the viewed film. However, those viewing antihero films managed to develop high levels of "liking" from a low starting point. Similarly to Versace viewers, participants experienced a more fluctuating range of affect over the course of the antihero narrative. It is easy to hypothesize that such story structures might appeal to an audience eager to have their preexisting story schemas challenged.

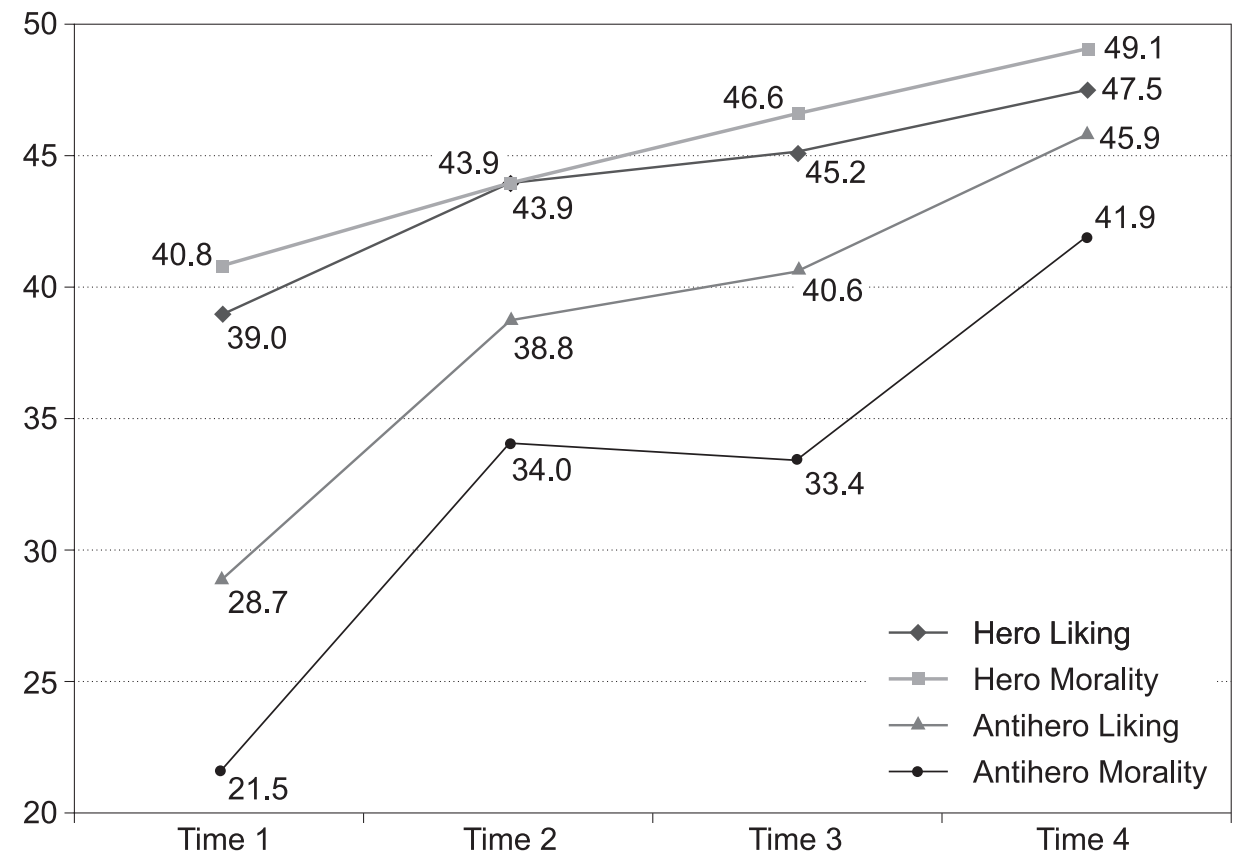

Figure 1: Liking and morality scores by condition across time ${ }^{8}$

Source: D. M. Shafer and A. A. Raney. 2012. "Exploring How We Enjoy Antihero Narratives.” Journal of Communication 62. 1033.

${ }^{8}$ In the study, participants rated their disposition towards the selected samples of the traditional hero and antihero, with The Rocketeer (1991) and Leon (1994) serving as the respective representatives. They addressed two items reflective of ADT's theoretical components: liking and moral evaluation. "The respondent's level of liking [was reflected by means of] a 51-point continuum ranging from hate (0) to neither (26) to love (50)." Moral evaluation was based on the respondents' judgment of "how good or evil the character seemed to be" using the same 51-point continuum (1032). 
Versace may be revealing of two reasons for the antisocial antihero's popularity. The first one pertains to the TV shows' creators. The changes that have affected TV production and distribution enabled makers to utilize a cinematic language appropriate for the telling of complex narratives, including the use of various empathy facilitators. As early as the 1990's the TV industry began to recognize the demand for higher narrative value. HBO's $O z$ (1997-2003) and The Sopranos (1999-2007) are often cited amongst those who set a new standard in TV writing. Other networks, like the AMC and FX, responded by producing original content, the result of which were The Shield (2002-2008), Mad Men (2007-2015) Breaking Bad (2008-2013), and others (Caruso). Quality shows became defined by a "slow construction of the fictional world, development of character, [and] attention to details." This was in part, due to the increasing number of novelists who began reinforcing the ranks of TV writers and executives; notable examples include Noah Hawley, Tom Perrotta, and Nic Pizzolatto (Biasio).

An important juncture was Netflix's production, House of Cards (2013-2018). The show's executive producer, David Fincher, is often credited with having set the series's tone. He was the first of many film directors involved with the series; other names include James Foley, Jodie Foster, and Agnieszka Holland (House). The show's lead actor, Kevin Spacey, on the other hand, was one of the first "Hollywood heavyweights" to act in a TV series (Caruso). The success of this "cinematic" production not only allowed Netflix to regain financial stability but also set the precedent for the likes of Versace (see Auletta; Carr).

The long format of the series, being closer to that of a novel than a film, allows viewers more time to experience evolving dispositions towards characters. It is, therefore, an ideal medium to incite a deeper evaluation of more complex protagonists. More screen-time allows writers to build rapport more effectively with less traditional heroes. Smith, himself the author of several novels, was allowed enough creative liberty to, as he says, "experiment with the structure" (Smith). It seems that today's circumstances favour the storytellers' tastes and preferences. While those vary, it is fair to assume that artists are prone to test the boundaries of their mediums. Thus the challenge of manipulating an audience into empathizing with an increasingly morally deficit antihero might seem an exciting prospect, and is therefore commonly pursued.

The second reason for the sociopathic protagonist's popularity pertains to the viewers' expectations. Streaming-media platforms, such as Hulu or Netflix, extend companies' reach to niche audiences worldwide. Their consumer data analysis strategies allow them to identify users' tastes, allowing prognosis to be made concerning their hedonic or eudaemonic motivation (see Arnold). It was this access, that afforded Netflix the foresight to encourage Fincher and Spacey's collaboration (Auletta). Streaming shows, whether classic or contemporary, have the dual role of being a product and a commercial-viability gauge for genres, narrative-types, and creatives. By increasing their capabilities of reaching and categorizing consumers, 
streaming-media providers are able to anticipate and market less conventional products. On the other hand, their users constitute the most narrative-exposed audience in world history (Matrix 124). These so-called "binge-watchers" have extensive familiarity with various narrative formats; as can be expected, their story schemas extend beyond the traditional narrative forms. Being the most demanding audience, streaming-media users are likely to respond enthusiastically to narratives that continue to challenge their expectations not only by providing surprising plot twists but also by allotting them a wider range of emotional experiences, such as the described dissonant affective response (Alexander).

\section{Conclusion and future study}

Unique technological and economic conditions have resulted in more creative freedom for storytellers. Their willingness to create challenging narratives is met with positive viewer response. This sustains the popularity of the antisocial antihero in television. However, there are various other factors influencing narrative tastes that require more consideration. Those include the gaming industry's influence on the audience's relation to characters (notably the player option to shuffle their gaming race, sex or species); the atomizing effect of consumer and Internet cultures that make possible the paradoxical network of self-gratifying individuals who might find identification with egotistical protagonists appealing; cultural aspects such as "obsession" with violence and serial killers that bolster the demand for psychopathic characters (Schmid 27); a growing frustration with the mainstreaming of reverse-marginalization, or, alternatively, with Hollywood's eclectic efforts to compensate for its underrepresentation of minorities. Aside from the factors related to tastes, due consideration should be given to the way exposure to the increasingly antisocial characters is affecting viewers.

\section{References}

Alexander, N. 2016. “Catered to Your Future Self: Netflix's 'Predictive Personalization' and Mathematization of Taste." In: McDonald, K., and D. Smith-Rowsey (eds.). The Netflix Effect: Technology and Entertainment in the 21st Century. London: Bloomsbury. Retrieved from https://www.bloomsbury.com/us/the-netflix-effect-9781501309441/. 23 Mar. 2019.

Arnold, S. 2016. "Netflix and the Myth of Choice/Participation/Autonomy." In: McDonald, K., and D. Smith-Rowsey (eds.). The Netflix Effect: Technology and Entertainment in the 21st Century. London: Bloomsbury. Retrieved from https://www.bloomsbury.com/us/the-netflix-effect-9781501309441/. 23 Mar. 2019.

Auletta, K. 2014. "Outside the Box: Netflix and the Future of Television." The New Yorker. Retrieved from https://www.newyorker.com/magazine/2014/02/03/outside-the-box-2. 23 Mar. 2019. 
Carr, D. 2013. "The Media Equation: TV Foresees its Future. Netflix is There.” The New York Times. Retrieved from https://www.nytimes.com/2013/07/22/business/media/tv-foresees-its-futurenetflix-is-there.html? r=0. Web. 25 Mar. 2019.

Caruso, J. 2017. "What's Behind Big-Name Actors' Migration To Television." The Federalist. Retrieved from https://thefederalist.com/2017/03/30/whats-behind-big-name-actors-migrationtelevision/. 2 Feb. 2019.

De Biasio, A. 2017. "Contemporary Television Series and Literature: An Intense, Transformative Embrace." Fusion Magazine. Retrieved from https://www.fusionmagazine.org/contemporary-television-series-and-literature-an-intense-transformative-embrace/. 2 Feb. 2019.

Dietz, J. 2017. "Best of 2017: Television Critic Top Ten Lists." Metacritic. Retrieved from https:// www.metacritic.com/feature/critics-pick-the-top-10-best-tv-shows-of-2017. 12 Jan. 2019.

Duncan, P. 2006. Film Noir. Harpenden: Pocket Essentials.

Ferens, D. 2016. "Belated Interest: Reading the Fiction of Sigrid Nunez Through Silvian Tomkin's Affect Theory." In: Drąg, W., and E. Kębłowska-Ławniczak (eds.). Spectrum of Emotions: From Love to Grief. Frankfurt am Main: Peter Lang.

Flory, D. 2008. Philosophy, Black Film, Film Noir. University Park: Pennsylvania State: UP.

Grant, B. K. 2007. Film Genre: From Iconography to Ideology. London: Wallflower Press.

Horwath, A. 2004. "A Walking Contradiction (Partly Truth and Partly Fiction)." In: Elsaesser, T., A. Horwath and N. King (eds.). The Last Great American Picture Show: New Hollywood Cinema in the 1970s. Amsterdam: Amsterdam UP, 83-106.

"House of Cards (2013-2018) Full Cast \& Crew." IMDb. Retrieved from https://www.imdb.com/ title/tt1856010/fullcredits. 13 May 2019.

Iglesias, K. 2005. Writing for Emotional Impact: Advanced Dramatic Techniques to Attract, Engage, and Fascinate the Reader from Beginning to End. Livermore: WingSpan Press.

Janicke, S. H., and A. A. Raney. 2015. "Exploring the Role of Identification and Moral Disengagement in the Enjoyment of an Antihero Television Series." Communications 40.4. 485-95.

Krakowiak, K. M., and M. Tsay-Vogel. 2011. "The Role of Moral Disengagement in the Enjoyment of Real and Fictional Characters." International Journal of Arts and Technology 4.1. 90-101.

Kraszewski, J. 2010. The New Entrepreneurs: An Institutional History of Television Anthology Writers. Middletown: Wesleyan UP.

Langford, B. 2005. Film Genre: Hollywood and Beyond. Edinburgh: Edinburgh UP.

-. 2010. Post-Classical Hollywood: Film Industry, Style and Ideology Since 1945. Edinburgh: Edinburgh UP.

Matrix, S. 2014. "The Netflix Effect: Teens, Binge Watching, and On-Demand Digital Media Trends." Jeunesse: Young People, Texts, Cultures 6.1. 119-36.

McDonagh, M. 2004. "The Exploitation Generation. Or: How Marginal Movies Came in From the Cold." In: Elsaesser, T., A. Horwath and N. King (eds.). The Last Great American Picture Show: New Hollywood Cinema in the 1970s. Amsterdam: Amsterdam UP, 107-30.

Oliver, M. B., and A. A. Raney. 2011. "Entertainment as Pleasurable and Meaningful: Identifying Hedonic and Eudaemonic Motivations for Entertainment Consumption." Journal of Communication 61. 984-1004.

Raney, A. A., and J. Bryant. 2002. "Moral Judgment and Crime Drama: An Integrated Theory of Enjoyment." Journal of Communication 52. 402-15.

Schmid, D. 2005. Natural Born Celebrities: Serial Killers in American Culture. Chicago: Chicago UP. Shadoian, J. 2003. Dreams and Dead Ends: The American Gangster Film. Oxford: Oxford UP.

Shafer, D. M., and A. A. Raney. 2012. "Exploring How We Enjoy Antihero Narratives." Journal of Communication 62. 1028-46.

Simmons, D. 2008. The Anti-Hero in the American Novel. New York: Palgrave Macmillan. 
Smith, T. R. 2018. “'The Assassination of Gianni Versace' Writer Tom Rob Smith Reveals Finale Secrets" [Video file]. Gold Derby. Retrieved from https://www.youtube.com/watch?v=2s2KPGRSPZw\&t=624s. 6 Jan. 2019.

Stout, M. 2005. The Sociopath Next Door: The Ruthless vs. the Rest of Us. New York: Broadway Books.

Vaage, M. B. 2010. "Fiction Film and the Varieties of Empathic Engagement." Midwest Studies in Philosophy 34. 158-79.

Zillmann, D., and J. Cantor. 1976. “A Disposition Theory of Humor and Mirth.” Humor and Laughter: Theory, Research and Applications. London: John Wiley \& Sons, 93-115. 